\title{
ТЕНДЕНЦИИ РАЗВИТИЯ ПРЕДПРИНИМАТЕЛЬСТВА НА РЫНКЕ МОЛОКА И МОЛОЧНОЙ ПРОДУКЦИИ СТАВРОПОЛЬСКОГО КРАЯ
}

Повыпение эффективности молочной отрасли является ваэсным условием повышения качества жизни населения и социальной стабильности, а также продовольственной безопасности страны. Исследование содержит актуальную сравнительную информацию о российском и региональном рынках молока и молочной продукции (на примере Ставропольского края). Целью исследования является оченка состояния молокопродуктового рынка и определение направлений его развития. В работе представлены изученная ситуачия на рынке молока и молочной продукции, информация об объемах производства молока по годам, дана оченка основных участников рынка, характеристика их деятельности и перспективы ее развития.

Ключевые слова: региональный рынок, спрос, молоко, молочная продукция, потребители, развитие отрасли.

Lomakina Anna Nikolaevna

TRENDS IN THE DEVELOPMENT OF ENTREPRENEURSHIP IN THE MARKET OF MILK AND DAIRY PRODUCTS IN THE STAVROPOL TERRITORY

Improving the efficiency of the dairy industry is an important condition for improving the quality of life of the population and social stability, as well as food security of the country. The study contains upto-date comparative information on the Russian and regional markets of milk and dairy products (using the example of the Stavropol Territory). The aim of the study is to assess the state of the dairy market and determine the directions of its development. The paper studies the situation on the market of milk and dairy products, provides information on production volumes by years, gives an assessment of the main market participants, as well as the characteristics of their activities and prospects for its development.

Key words: regional market, demand, milk, dairy products, consumers, industry development

Bведение / Introduction. Ставропольский край является развитым сельскохозяйственным регионом нашей страны. Однако на сегодняшний день его достижения сконцентрированы исключительно в области растениеводства [11]. По большинству показателей молочной отрасли регион находится на низком уровне. Последние годы были тяжелыми как для ставропольской молочной отрасли, так и для российской в целом. Однако кризис, падение курса национальной валюты, запрет на ввоз иностранного сырья и готовой продукции имели как отрицательное, так и положительное влияние на молочную отрасль края. Негативными внутренними факторами и общероссийского рынка молока, и региональных рынков стали дорогостоящие кредиты, низкая рентабельность, а также недостаточная со стороны государства поддержка фермеров и индивидуальных предпринимателей [1]. Положительным является высвобождение значительной доли молочного рынка за счет снижения импортных поставок.

Maтериалы и методы /Materials and methods. Уровень потребления молочной продукции в 2018 г. в России вернулся к показателям докризисного периода - 250 кг на человека в год. Производители молока считают, что этого все равно недостаточно, поскольку данная цифра по-прежнему существенно отстает от нормы, утвержденной Минздравом России в августе 2016 г. - 325 кг. Однако по данным Международной молочной федерации 2015 г., в России на одного человека 
пришлось лишь 173 кг молока в год, в 2018 г. этот показатель увеличился до 230,9 кг, тем не менее эта цифра отстает от международных стандартов потребления молока и молочных продуктов почти в два раза (медицинская норма потребления - 392 кг).

По потреблению молока и молочных продуктов Ставропольский край находится только на 50 месте среди регионов нашей страны. В 2018 г. данный показатель составил 212, 6 кг/год в среднем на человека, что составляет 65 \% от нормы. Причем в последние годы потребление молочных продуктов падает, в 2014 году их потребление составило 217 кг/год на человека.

Производство молока в России по итогам 2018 г. составило 30,6 млн т, что на 455 тыс. т, или на $1,5 \%$ больше показателя 2017 г. В том числе в сельхозорганизациях выпуск увеличился на $3,6 \%$ - до 16,2 млн т, в фермерских хозяйствах - на $5 \%$ - до 2,5 млн т. В хозяйствах населения производство снизилось на $1,8 \%$ - до 11,9 млн т.

Географически производители молока распределены неравномерно: около 50 \% предприятий находятся в Цетральном федеральном округе, четверть - в Приволжском ФО. На долю Ставропольского края приходится лишь 2,2 \% от общероссийского об̆ъема производства молока (680,2 тыс. т сырого молока). Это ставит его на 12 место среди других регионов России, в то время как соседний Краснодарский край на третьем месте по производству молока.

Среди макрорегионов наибольшую динамику в производстве молока показал Центральный федеральный округ, где производство увеличилось на 4,1 \% - до 5,7 млн т, а таюже Южный федеральный округ - на 2,2 \% - до 3,7 млн т.

В молочной отрасли Ставропольского края не все так хорошо: в последние годы в регионе наблюдается спад производства: в 2014 году было произведено 686,8 тыс. т, в 2015 г. $-687,4$ тыс. т, 2016 г. $-680,2$ тыс. т, а в 2017 г. $-640,8$ тыс. т, в 2018 г. - 632 тыс. т сырого молока. Таким образом, объемы за год снижались на $0,1-0,7 \%$ [14].

Снижается и поголовье коров: если в 2014 г. оно составляло 203 тыс. гол., в 2015 незначительно выросло до 204,2 тыс. гол., а в 2016 году вновь упало до 198,7 тыс. голов. Племенных коров молочного направления всего $13,1 \%$.

Продуктивность коров тоже находится на скромном уровне даже по среднероссийским меркам - 4478 кг/год на корову в 2014 году; 4537 кг/год - в 2015 г. - 6346 кг/год, 2016г. 6336 кг/год, 2017 г. - 6641 кг/год. В среднем по России - 4134 кг/год. Ранее этот показатель был значительно выше: в ставропольских сельскохозяйственных организациях - 6208 кг/год, в среднем по России - 5140 кг/год [14].

Peзультаты и обсужсдение / Results and discussion. Вероятно, скромные достижения Ставропольского края можно объяснить падением господдержки. Если в 2014 году на молочную отрасль выделили 306,2 млн рублей, то в 2015 году - 266 млн рублей, а в 2016 году - 251,7 млн рублей, из них федеральный бюджет предоставил 214 млн рублей. В 2017 году краевые власти увеличили инвестиции в сельское хозяйство на 300 млн рублей (25\%) - до 6,8 млрд рублей. Значительный объем дополнительных средств будет направлен на поддержку молочного и мясного животноводства, признанных главными целями субсидирования. Благодаря дополнительной помощи руководство региона рассчитывает в ближайшие 5 лет увеличить поголовье коров вдвое [12].

В начале 2018 года в результате сельхозпереписи скорректированы полученные данные по производству молока во всей стране: валовой надой молока в 2017 г. во всех хозяйствах отрасли оказался ниже на 1 млн т, в результате чего уровень самообеспеченности всего населения молоком и молочной продукцией уменьшился с 81,3\% до 80,8 \% в 2017 году. Пороговый показатель доктрины продовольственной безопасности находится на уровне $90 \%$.

Ставропольский край производит лишь 78 \% молока от потребности. Если подсчитать, сколько килограммов этого важного продукта приходится на каждого жителя края, получается 225 кг - это $71 \%$ от медицинской нормы [9]. 
Ни один сельхозпроизводитель Ставропольского края не входит в Топ-50 молочных хозяйств РФ «Союзмолоко». Среди ставропольских производителей можно отметить ООО «Колхоз-племзавод имени Чапаева». Поголовье КРС в нем составляет 3326 голов, в том числе 1250 коров. Валовое производство молока в данном хозяйстве в 2016 г. составило 7519 т, а надой на одну корову составил 6188 кг. До 2022 года на предприятии планируется увеличить поголовье молочных коров до 1290 голов и увеличить годовой объем производства молока до 9030 т, с ростом на $6 \%$ по сравнению с 2018 г.

Среди агропредпринимателй, производящих молоко, можно отметить ООО СП «Чапаевское», СПК «Колхоз-племзавод Казьминский», ООО «АПХ Лесная дача», СХ ЗАО «Радуга» [7].

Основным поставщиком молока являются личные подсобные хозяйства. На долю коллективных хозяйств приходится меньше половины производимого молока [10].

Сбором молока у населения занимаются индивидуальные предприниматели (перекупщики), значительная часть от выручки оседает в их карманах. В начале 2018 года за каждый литр молока перекупщики платили владельцам коров по 20 рублей. Это невысокая цена, если учесть, что себестоимость литра молока составляет 21 рубль, поэтому резко упало производство молока в личных подсобных хозяйствах (ЛПХ). Работать в убыток нет смысла.

Причиной падения закупочных цен на молоко явились большие партии сухого молока, поступившие из Новой Зеландии, ранее сухое молоко шло транзитом через Белоруссию из Европы. Перерабатывающие предприятия пополнили запасы сухого молока до максимальных объёмов и снизили закупки натурального молока. Использовать сухое молоко прибыльнее, т. к. оно гораздо дешевле - от 100 до 104 рублей за килограмм, а в пересчёте на натуральное молоко соответствует 10-11 рублям, что значительно ниже себестоимости натурального молока.

Сельскохозяйственным предприятиям за каждый литр молока переработчики платят 21 руб., фермерским хозяйствам - 18 руб., а владельцам личных подсобных хозяйств - только по 15 руб. Данная ситуация является откровенной дискриминацией, т. к. для многих владельцев ЛПХ продажа молока является единственным средством к существованию.

Федеральная власть призывает крестьян больше производить молока, а защитить их от произвола перекупщиков и переработчиков не может. Ведь для крупных хозяйств снижение закупочных цен не очень чувствительно, а для многих личных подсобных хозяйств это прямой путь к разорению [3].

В Ставропольском министерстве сельского хозяйства разрабатывают проект по созданию крестьянских кооперативов. Личное подсобное хозяйство - это семья, которая держит на своём подворье 2-3 молочные коровы. Из-за небольшого количества молока владелец ЛПХ не может ежедневно напрямую отправлять это молоко на завод. Ему проще продать его перекупщикам. Продавая продукцию посредникам, владельцы ЛПХ теряют значительную часть прибыли. Посредники, скупая молоко по 13-15 рублей за литр, обеспечивают себе высокий уровень доходности. При этом производители терпят убытки.

Стремясь реализовать молоко по более выгодной цене, производители продают молоко в другие регионы. Ежегодно за пределы Ставрополья на перерабатывающие предприятия Краснодарского края, Адыгеи, Карачаево-Черкесии, Ростовской области и даже Калмыкии вывозится до 15 тыс. т ставропольского молока. Хотя загруженность мощностей молокоперерабатывающих предприятий края $-47 \%$. Всего в Ставропольском крае работает 12 молокоперерабатывающих предприятий, из них $\mathrm{AO}$ «Молочный комбинат Ставропольский» - крупнейший на юге России и в Ставропольском крае завод по переработке молока, который закупает сырье практически у половины крупных производителей Ставропольского края. Комбинат может перерабатывать до 400 т молока в сутки и производит более чем пятьсот наименований продукции [8].

В регионе также работают известный сыродельный завод ОАО «Сыродел», ООО «Молоко», ООО «Хладонеж», ООО «Вита 1» и др. 
Запретить крестьянам продавать свою продукцию в другие регионы власти края не могут, поскольку федеральный закон об основах государственного регулирования торговой деятельности не позволяет властям вводить какие-либо ограничения. Но сам факт, что молоко увозят, оказывает отрицательное влияние на работу местных молокоперерабатывающих предприятий [5].

Поэтому необходимо стимулировать интеграционные процессы в молочной отрасли, объединяясь в кооперативы [2]. Примером удачной кооперации может послужить опыт Липецкой области, в которой сегодня более $70 \%$ сельских жителей области являются членами кооперативов. Ставропольским крестьянам для стабилизации ситуации необходимо создавать молочные кооперативы, чтобы выгодно продавать и молоко, и другую продукцию, вытесняя посредников с рынка. И такая работа ведётся. Для разработки дорожной карты по формированию кооперативов Ставропольского кря собран банк данных по суточным надоям молока. Наметились положительные тенденции по реализации молока у владельцев ЛПХ Апанасенковского, Ипатовского, Степновского районов.

Позитивные тенденции развития в производстве молока прослеживаются и в фермерских хозяйствах Ставропольского края. С 2012 по 2018 гг. производство молока в них выросло в два раза. В 2018 г. численность поголовья в фермерских хозяйствах превысила 7,5 тыс. коров. В этом году по инициативе краевых властей на гранты выделяется 817 млн руб. Из них 571 млн руб. пойдёт на поддержку семейных молочных ферм, а 124 млн руб. - на кооперацию. На грантовую поддержку также рассчитывают три молочных кооператива: «Алексеевский» Благодарненского, «Новокавказский») Александровского и «ЭКОПРОДУКТ Вознесеновский» Апанасенковского районов [12].

К 2021 году дойное стадо в крупных сельскохозяйственных организациях вырастет до 28 тыс. голов. В крае строятся две крупные молочно-товарные фермы, где будут содержаться свыше 4000 коров. Одна из этих ферм начала работу в 2018 году, а вторая - в 2019 году. За три года производство молока может вырасти на $15 \%$. То есть к 2021 году Ставропольский край планирует производить не менее 700 тыс. т молока при условии, что руководители хозяйств отнесутся к проблеме со всей ответственностью, так как это делают в Кочубеевском, Новоалександровском, Предгорном районах. К сожалению, в девяти районах края от производства молока отказались совсем, считая его нерентабельным [13].

Но заниматься молоком всё равно рано или поздно придётся, при этом ставку следует делать только на высокотехнологичное производство, как, например, в хозяйстве «Россия» Новоалександровского района, где ежегодно производят около 7 тыс. т первосортного молока. Все технологические процессы на фермах хозяйства механизированы, ручной труд исключён фактически полностью.

Внедрение передовых технологий на молочных фермах - одна из приоритетных задач, стоящих перед молочной отраслью, именно они позволят вывести отрасль на качественно новый уровень [6].

И, конечно, без поддержки государства молочную отрасль не поднять. Особенно в этом нуждаются малые формы хозяйствования. В Ставропольском крае успешно реализуется программа по поддержке начинающих фермеров и созданию семейных животноводческих ферм. В частности, по программе «Начинающий фермер» предоставляются гранты на 1,5 млн руб. для строительства фермы, приобретения техники, доильного оборудования и племенных животных [4].

Заключение / Conclusion. Конъюнктура общемирового рынка, санкции и ослабленный рубль обеспечивали рентабельность молочной отрасли, однако в настоящее время эти факторы себя практически исчерпали.

Модернизация молочного производства, инвестиции в генетический фонд и современные технологии обеспечивают конкурентоспособность на внутреннем рынке. В настоящее время в молочной отрасли модернизированы и соответствуют современным стандартам 40-50\% производителей молока, 60-70\% переработчиков.

Немаловажную роль играет государственная деятельность по регулированию рынка, а также решение вопросов, связанных с продолжительностью и прозрачностью государственной поддержки. Меры государственной поддержки должны быть направлены на обеспечение инвестиционной привлекательности отрасли и оптимизацию операционной деятельности. 
В целом молочная отрасль имеет хороший потенциал для развития как в области производства, так и в переработке. С точки зрения внутреннего молокопродуктового рынка в течение ближайшего десятилетия объем потребления молока в нашей стране может вырасти до $30 \%$. С точки зрения развития экспортного потенциала российские молочные продукты могут быть конкурентоспособны на многих рынках, поэтому сельхозтваропроизводителям необходимо открывать эти рынки и завоёвывать их.

\section{ЛИТЕРАТУРА И ИНТЕРНЕТ-РЕСУРСЫ}

1. Васюкова, В. А. Стратегические траектории развития при защите интересов субъектов информационных отношений в сфере услуг / В. А. Васюкова, И. В. Воробьева, А. Н. Ломакина // Научный вестник Государственного автономного образовательного учреждения высшего профессионального образования «Невинномысский государственный гуманитарно-технический институт». - 2018. - № 2. - С. 94-97.

2. Дементьева А. Н. Интеграция как инструмент повышения эффективности предпринимательских структур / А. Н. Дементьева // Достижения науки и техники АПК. - 2006. - № 6. - С. 55-56.

3. Дементьева А. Н. Развитие предпринимательской деятельности на региональном рынке молока и молокопродуктов (на материалах Ставропольского края) : дис. ... канд. экон. наук / А. Н. Дементьева. - Ставрополь, 2006.

4. Информационный портал «Региональное законодательство». - URL: http:// www.regionz.ru

5. Лихонина О. А. Особенности управления сельскохозяйственными рисками с использованием системы интегрированного страхования / О. А. Лихонина // Управление в социальных и экономических системах. - 2015. - № 24. - С. 83-84.

6. Ломакина А. Н. Инновационные стратегии развития - инструмент повышения эффективности деятельности предпринимательских структур в молочной промышленности / А. Н. Ломакина // Концепт: научно-методический электронный журнал. - 2013. - Т. 3. - C. 2951- 2955. - URL: http:// e-koncept. ru/2013/53596.htm.

7. Ломакина А. Н. Территория опережающего развития как фактор повышения инвестиционной привлекательности моногорода / А. Н. Ломакина // Вестник Северо-Кавказского федерального университета. - 2018. - № 4 (67). - С. 40-47.

8. Ломакина А. Н. Исследования регионального рынка молока и молочной продукции / А. Н. Ломакина, С. Ю. Шамрина, Е. П. Манчук // Kant. - 2018. - № 3 (28). - С. 192-196.

9. Ломакина А. Н. Аспекты маркетинговых исследований услуг с учетом их специфических характеристик / А. Н. Ломакина // Проблемы научной мысли. - 2019. - Т. 3. - № 1. - С. 28-30.

10. Ломакина А. Н. Тенденции развития предпринимательства на региональном молокопродуктовом рынке Ставропольского края / А. Н. Ломакина // Молодежная наука в развитии регионов : материалы II Всероссийской конференции студентов и молодых ученых с международным участием / под ред. Н. П. Нечаева. - Пермь : Пермский национальный исследовательский политехнический университет, 2012. - C. 439-442.

11. Манчук Е. Проблемы экономического развития региона и способы их преодоления в современных условиях (на примере Ставропольского края) / Е. Манчук, Н. Коваленко, А. Ломакина // Предпринимательство. - 2015. - № 2. - С. 114-125.

12. Официальный сайт «Портал госпрограмм PФ». - URL: https://programs.gov.ru/

13. Официальный сайт Министерства сельского хозяйства Ставропольского края. - URL: http:// www. mshsk.ru - (дата обращения 17.06.2019)

14. Ставропольстат - Федеральная служба государственной статистики. - URL: http:// www stavstat.gks. ru (дата обращения 17.06.2019)

\section{REFERENCES AND INTERNET RESOURCES}

1. Vasyukova V. A. Strategicheskiye trayektorii razvitiya pri zashchite interesov sub»yektov informatsionnykh otnosheniy v sfere uslug (Strategic development paths while protecting the interests of subjects of information relations in the service sector) / V. A. Vasyukova, I. V. Vorob'yeva, A. N. Lomakina // Nauchnyy vestnik Gosudarstvennogo avtonomnogo obrazovatel'nogo uchrezhdeniya vysshego professional'nogo obrazovaniya «Nevinnomysskiy gosudarstvennyy gumanitarno-tekhnicheskiy institut». - 2018. - № 2. - S. 94-97. 
2. Dement'yeva A. N. Integratsiya kak instrument povysheniya effektivnosti predprinimatel'skikh struktur (Integration as a tool to increase the effectiveness of entrepreneurial structures) / A. N. Dement'yeva // Dostizheniya nauki i tekhniki APK. - 2006. - No 6. - S. 55-56.

3. Dement'yeva A. N. Razvitiye predprinimatel'skoy deyatel'nosti na regional'nom rynke moloka i molokoproduktov (na materialakh Stavropol'skogo kraya) (Development of entrepreneurial activity in the regional market of milk and dairy products (based on materials from the Stavropol Territory) : dis. ... kand. ekon. nauk / A. N. Dement'yeva. - Stavropol', 2006.

4. Informatsionnyi portal «Regional'noye zakonodatel'stvo». - URL: http://www.regionz.ru

5. Likhonina $\mathrm{O}$. A. Osobennosti upravleniya sel'skokhozyaystvennymi riskami s ispol'zovaniyem system yintegrirovannogo strakhovaniya (Features of management of agricultural risks with the use of the integrated insurance system) / O. A. Likhonina // Upravleniye v sotsial'nykh i ekonomicheskikh sistemakh. 2015. - No 24. - S. 83-84.

6. Lomakina A. N. Innovatsionnyye strategii razvitiya - instrument povysheniya effektivnosti deyatel'nosti predprinimatel'skikh struktur $\mathrm{v}$ molochnoy promyshlennosti (Innovative development strategies $-\mathrm{a}$ tool to increase the effectiveness of entrepreneurial structures in the dairy industry) / A. N. Lomakina // Kontsept: nauchnometodicheski yelektronnyy zhurnal. - 2013. - T. 3. - S. 2951-2955. - URL: http:// e-koncept. $\mathrm{ru} / 2013 / 53596 . \mathrm{htm}$.

7. Lomakina A. N. Territoriya operezhayushchego razvitiya kak faktor povysheniya investitsionnoy privlekatel'nosti monogoroda (The territory of accelerated development as a factor in increasing the investment attractiveness of a single-industry town) / A. N. Lomakina // Vestnik Severo-Kavkazskogo federal'nogo universiteta. - 2018. - № 4 (67). - S. 40-47.

8. Lomakina A. N. Issledovaniya regional'nogo rynka moloka i molochnoy produktsii (Studies of the regional market of milk and dairy products) / A. N. Lomakina, S. YU. Shamrina, Ye. P. Manchuk // Kant. - 2018. № 3 (28). - S. 192-196.

9. Lomakina A. N. Aspekty marketingovykh issledovaniy uslug s uchetom ikh spetsificheskikh kharakteristik (Aspects of marketing research of services taking into account their specific characteristics) / A. N. Lomakina // Problemy nauchnoy mysli. - 2019. - T. 3. - № 1. - S. 28-30.

10. Lomakina A. N. Tendentsii razvitiya predprinimatel'stva na regional'nom molokoproduktovom rynke Stavropol'skogo kraya (Tendencies of entrepreneurship development in the regional dairy products market of the Stavropol Territory) / A. N. Lomakina // Molodezhnaya nauka v razvitii regionov : materialy II Vserossiyskoy konferentsii studentov i molodykh uchenykh s mezhdunarodnym uchastiyem / pod red. N. P. Nechayeva. Perm': Permskij nacional'nyj issledovatel'skij politekhnicheskij universitet, 2012. - S. 439-442.

11. Manchuk Ye. Problemy ekonomicheskogo razvitiya regiona i sposoby ikh preodoleniya v sovremennykh usloviyakh (na primere Stavropol'skogo kraya) (Problems of economic development of the region and ways to overcome them in modern conditions (the example of the Stavropol Territory)) / Ye. Manchuk, N. Kovalenko, A. Lomakina // Predprinimatel'stvo. - 2015. - No 2. - S. 114-125.

12. Ofitsial'nyi sait «Portal gosprogramm RF». - URL: https:// programs.gov.ru

13. Ofitsial'nyi sait Ministerstva sel'skogo khozyaystva Stavropol'skogo kraya. - URL: http:// www.mshsk.ru

14. Stavropol'stat - Federal'naya sluzhba gosudarstvennoy statistiki [Elektronnyi resurs]. - URL: http:// www stavstat.gks.

\section{СВЕДЕНИЯ ОБ АВТОРЕ}

Ломакина Анна Николаевна, кандидат экономических наук, доцент кафедры экономики и менеджмента, Невинномысский институт экономики, управления и права, Невинномысск. E-mail: annancfu@ yandex.ru

\section{INFORMATION ABOUT AUTHOR}

Anna Lomakina, Candidate of Economic Sciences, associate Professor of the Department of Economics and Management, Nevinnomyssk Institute of Economics, Management and Law, Nevinnomyssk. E-mail: annancfu@yandex.ru 